Halliwell, G. (1957). J. gen. Microbiol. 17, 153-165

\title{
Cellulolysis by Rumen Micro-organisms
}

\author{
BY G. HALLIWELL
}

The Rowett Research Institute, Bucksburn, Aberdeenshire

\begin{abstract}
SUMMARY: The optimal conditions for accurate and reproducible analysis of cellulose hydrolysis by micro-organisms, particularly from the rumen, were determined. Rumen micro-organisms were found to require approximately $50 \mathrm{mg}$. substrate (cellulose powder) in a $40 \mathrm{hr}$. incubation at $37^{\circ}$ with $1 \mathrm{ml}$. of rumen liquor, and a total volume of $8 \mathrm{ml}$., in static vessels. All types of cellulose or simpler substituted derivatives, from soluble carboxymethylcellulose through insoluble cellulose powder to cotton fibres, are nearly quantitatively hydrolysed by mixed rumen micro-organisms. The effect of the inorganic composition of the medium, of antibacterial agents (thymol, fluoride, toluene) and of concentration procedures on the cellulolytic activity of rumen micro-organisms was examined. Rumen protozoa appear to play a minor role in cellulose degradation; their effective activity is due mainly to closely associated, possibly ingested, bacteria. The validity of the results obtained by various methods of 'cellulase' assay is discussed.
\end{abstract}

Much of the earlier work on cellulose metabolism in the rumen has been devoted to examination of the final products of digestion, with particular emphasis on the fatty acids formed (for reviews see Phillipson, 1953; Phillipson \& Cuthbertson, 1956). In order to investigate the mechanism of action of cellulose-decomposing enzymes a new approach seems to be required, and in the work described below emphasis is placed on a less well-known stage of cellulose metabolism, namely the primary degradation of cellulose. This stage was chosen because all subsequent stages, including production of many and varied products, depend on it. Although some micro-organisms can readily solubilize the most complex forms of cellulose no one has yet succeeded in obtaining cell-free extracts having this property. On the other hand, many workers have prepared extracts (both from cellulolytic and non-cellulolytic organisms) which rapidly attack soluble cellulose derivatives, but which have little or no effect on insoluble forms of cellulose; the review by Siu (1951) provides many references to such examples. More recent examples have been collected in the list which follows and the percentage figure quoted for hydrolysis has been calculated (where possible) as a fraction of the initial amount of cellulose powder or cotton. Such 'cellulase' preparations have been obtained from fungi (Jermyn, 1952, 0.2\%; Nishizawa \& Kobayashi, 1953; Whitaker, 1953, $2 \%$; Aitken, Eddy, Ingram \& Weurman, 1956, $6 \%$; Basu \& Pal, 1956, $4 \%$; Higa, O'Neill \& Jennison, 1956; Thomas, 1956, $5 \%$ ), from rumen bacteria (Halliwell, 1954, unpublished, $10 \%$; Kitts \& Underkofler, 1954, $3 \%$ ) and from animals such as the limpet, Patella vulgata (Festenstein \& Halliwell, $1955,4 \%$, unpublished). Walseth (1952) appears to be the only worker to have obtained appreciable action (60\% hydrolysis in $40 \mathrm{hr}$.) on an insoluble, though slightly degraded, cellulose. The degree of hydrolysis depended, how- 
ever, on the extent of treatment with concentrated phosphoric acid. Walseth's extract was obtained from a commercial supply of Aspergillus niger which, however, is no longer available.

In the field of rumen cellulolysis the problem is further complicated by the necessity for anaerobiosis. Attempts made to isolate cellulolytic bacteria from the rumen have invariably used degraded or hydrolysed forms of cellulose such as the acid-treated $(11 \mathrm{~N}-\mathrm{HCl})$ and ball-milled cotton of Hungate $(1950 a, b)$ or the ball-milled filter-paper of Bryant \& Burkey (1953). Sijpesteijn (1951) similarly isolated Gram-positive streptococci which showed poor cellulolytic growth in pure culture on filter-paper. Hungate $(1950 a)$ summarized the work on cellulolytic micro-organisms by stating 'the low rate at which (chemically treated) cotton and filter-paper is digested in cultures does not imply that development in the rumen is thus limited'. However, it is clear that pure cultures of rumen micro-organisms show much less true cellulolytic efficacy as compared with the activity of mixed rumen micro-organisms.

It was evident that an investigation was required to determine the conditions necessary for the optimal rate of cellulolysis and of cellulase production by the rumen microflora. This has been attempted in the present work by using mixed cultures, which seem preferable for at least two reasons: (1) mixed cultures provide less divergence from in vivo conditions, perhaps because mixed enzymes from different organisms are required for cellulolysis; (2) our mixed cultures, unlike the pure strains used by other workers, act relatively rapidly and completely on all forms of insoluble cellulose tested. Finally, cellulose degradation has been determined by gravimetric analysis of residual cellulose; determination of the reducing sugars produced by rumen microorganisms in presence of antiseptics is not applicable, for such inhibitors decrease true cellulolytic activity as opposed to the action on soluble cellulose derivatives.

\section{METHODS}

Several different forms of cellulose were used:

Native cotton fibres (Peruvian Tanguis, kindly supplied by the British Cotton Industry Research Association) were used untreated, and also de-waxed as follows. Fibres were purified by Soxhlet extraction with redistilled ethanol for $8 \mathrm{hr}$. and with ether for $6 \mathrm{hr}$., followed by refluxing under nitrogen in $1 \%(w / v)$ sodium hydroxide for $8 \mathrm{hr}$. After washing with boiled water until neutral, washing was continued successively with cold water, $1 \%(\mathrm{v} / \mathrm{v})$ acetic acid, and water. The product was finally dried in air. Cellulose pozeder, referred to in the text as cellulose powder (Whatman), was standard grade ashless powder for chromatography and was used untreated. Swollen cellulose was prepared from absorbent cotton and also from cellulose powder (Whatman) by soaking in phosphoric acid (A.R., $90 \%$ ) at $1^{\circ}$ for $2 \mathrm{hr}$., followed by washing until acid and phosphate free (Walseth, 1952). Hydrocellulose was prepared from absorbent (de-waxed) cotton by immersion in $75 \mathrm{vol}$. of $11 \mathrm{~N}-\mathrm{HCl}$. (A.R.) for $48 \mathrm{hr}$. at $18^{\circ}$. After rejecting the supernatant fluid the fine powder was poured into water and then filtered off on a Buchner funnel, washed 
acid- and chloride-free and finally dried in vacuum at room temperature. A product similar to this has been widely used in work on cellulolytic microorganisms (Hungate, 1942, 1950 $a, b$; Sugden, 1953), after further degradative treatment by grinding.

\section{Sources of cellulolytic enzyme}

A. Rumen liquor. The animals used were Cheviot sheep fitted with a permanent rumen fistula. Daily diet comprised $500 \mathrm{~g}$ hay and $250 \mathrm{~g}$ grass cubes at 7 a.m. and at 4 p.m. with free access to water and salt lick. Rumen liquor (RL; not more than $1.5 \mathrm{l}$. in $24 \mathrm{hr}$. from one animal) was filtered through six layers of surgical gauze before use.

B. Rumen liquor supernatant fluid (R.L.S.) and rumen liquor concentrates (R.P.). R.L.S. was obtained by centrifugation of filtered rumen liquor at $20,000 \mathrm{~g}$ for $30 \mathrm{~min}$. at $1^{\circ}$. The clear brown supernatant fluid (R.L.S.) so obtained was entirely lacking in activity against all the forms of insoluble cellulose described above. The precipitated organisms from this centrifugation are designated R.P. in the sequel.

\section{Determination of the cellulolytic activity of rumen micro-organisms}

The standard assay for cellulolytic activity. Fifty mg. of insoluble cellulose (or $30 \mathrm{mg}$. with some forms of cellulose) was added to a $\mathrm{CO}_{\mathbf{2}}$-saturated, $\mathrm{NaHCO}_{3}+$ salts buffer (see below), with or without addition of rumen microorganisms $(1 \mathrm{ml}$.). The assay tubes, $150 \mathrm{~mm} . \times 15 \mathrm{~mm}$., were closed with a Bunsen valve. The total volume was made up to $8 \mathrm{ml}$. (initial $\mathrm{pH}$ value $6 \cdot 8$ ) and the tubes were incubated at $37^{\circ}$ for about $40 \mathrm{hr}$. Unless stated to the contrary, $\mathrm{NaHCO}_{3}$ buffer or medium had the following composition: $\mathbf{0 . 2} \mathrm{M}$ $\mathrm{NaHCO}_{3}$, $100 \mathrm{ml}$.; 0.154 M-KCl, $4 \mathrm{ml}$; 0.154 M- $\mathrm{KH}_{2} \mathrm{PO}_{4}, 1 \mathrm{ml}$.; 0.154 M-MgSO $1 \mathrm{ml}$; 0.154 M-( $\left.\mathrm{NH}_{4}\right)_{2} \mathrm{HPO}_{4}, 5 \mathrm{ml}$; $0 \cdot 11 \mathrm{M}-\mathrm{CaCl}_{2}, 3 \mathrm{ml}$. (Elsden, 1945).

Method of analysis of cellulose breakdown. Breakdown of insoluble cellulose was followed by gravimetric determination of the residual cellulose. Sintered glass filters (grade 3) were used, on which the residual cellulose was washed successively with $5 \mathrm{ml}$. volumes of $3.8 \mathrm{~N}-\mathrm{HCl}, 0.7 \mathrm{~N}-\mathrm{NH}_{4} \mathrm{OH}, 1 \%(\mathrm{w} / \mathrm{v})$ Teepol XL, and distilled ethanol (10 ml.), with a $20 \mathrm{ml}$. water-wash between each solvent. The residual cellulose was subsequently dried at $100^{\circ}$ for $16 \mathrm{hr}$. The author is indebted to Dr G. A. Levvy for details of this procedure. Control determinations with tubes containing insoluble cellulose and all reagents except micro-organisms did not show any loss of cellulose in periods up to 7 days at $37^{\circ}$, or any sign of microbial growth when examined in films stained by Gram's method. Results were corrected, where necessary for apparent endogenous cellulose of 'cellulase' preparations. After the standard solvent washing of cellulose + rumen liquor (R.L.) or precipitated organisms (R.P.), the endogenous cellulose of the microbial preparation was negligible in the case of rumen liquor and less than $4 \%$ of the weight of cellulose used in the assay, when using precipitated organisms (R.P.). In the text, the degradation of cellulose is given in terms of ' $\%$ hydrolysis' (cellulolysis). This indicates the fraction of the initial cellulose which had been solubilized. 


\section{RESULTS}

\section{Properties of rumen liquor and of rumen liquor organisms}

The conditions necessary to provide a uniform response in the determination of the cellulolytic activity of various preparations are illustrated in Figs. 1-3. It can be seen that maximal conditions for cellulose loss were met by using $50 \mathrm{mg}$. cellulose powder (Whatman; C.P.W.), $40 \mathrm{hr}$. incubation at $37^{\circ}$ and $1 \mathrm{ml}$. of rumen liquor in a total volume of $8 \mathrm{ml}$., in static vessels. Fig. 2 illustrates the importance of maintaining contact between the micro-organisms and the insoluble substrate for cellulolysis to occur. Shaking by itself (Warburg bath, 120 strokes/min., horizontal movement about $50 \mathrm{~mm}$.) apparently had no deleterious effect on the integrity of the rumen liquor organisms. This was shown by stopping the agitation, whereupon cellulolysis began again at the normal rate. Similar results were obtained when stoppered vessels were substituted for those equipped with Bunsen valves. This phenomenon was also seen on passing carbon dioxide through the tubes at a rate $\left(2 \mathrm{ml} . \mathrm{CO}_{2} / \mathrm{min}\right.$. $)$ sufficient to keep the cellulose + bacteria in suspension; when the flow of gas was stopped cellulose hydrolysis began again in the usual way.

Justification of the buffer medium used in the 'cellulase' assay appears in Table 1. Of the five salts present in the bicarbonate $+\mathrm{CO}_{2}$ buffer, only $\mathrm{MgSO}_{4}$ and $\left(\mathrm{NH}_{4}\right)_{2} \mathrm{HPO}_{4}$ were essential for cellulose decomposition. No improvement was found on varying the concentration of the other salts, nor was it possible to replace the bicarbonate by a $\mathrm{KH}_{2} \mathrm{PO}_{4}+\mathrm{NaOH}$ buffer of the same $\mathrm{pH}$ value. Addition of a reducing agent $\left(\mathrm{Na}_{2} \mathrm{~S}, \mathbf{0 . 0 3} \%\right.$, w/v) was not essential for optimal cellulolysis by rumen liquor nor by concentrates of the micro-organisms from the liquor (R.P.), provided that the bicarbonate + cellulose buffer mixture was thoroughly gassed with $\mathrm{CO}_{2}$ before and after addition of organisms. However, it was advisable to maintain anaerobiosis, because the system was extremely sensitive to oxidation, as shown by the completely inhibitory effect of ferricyanide. Although 'cellulase' was never detected in the rumen liquor surrounding the bacteria it was felt that this might be due to the labile nature of the enzyme system. In an attempt to stabilize possible free cellulolytic enzymes dilute gelatin was used as an addition to the standard assay medium. It did not, however, produce the desired stimulatory effect. The centrifuged supernatant fluid from rumen liquor (R.L.S.), which is itself inactive on cellulose, did not improve or decrease cellulolysis by rumen liquor or by the deposited organisms. Cellulolysis by the deposited organisms was as effective at $\mathrm{pH} 6.6$ as at the standard assay value of $\mathrm{pH} 6.8$, but a further decrease of $\mathrm{pH}$ value to $\mathbf{5 . 9}$ caused complete loss of cellulolytic activity. Although the above determinations were carried out on cellulose powder (Whatman) Fig. 1 indicates that rumen liquor was equally effective in producing almost complete solubilization of native cotton fibre.

\section{Instability of the cellulolytic activity of rumen micro-organisms}

Attempts to concentrate the cellulolytic enzyme of rumen liquor by centrifugation at $10,000 \mathrm{~g}$ for $30 \mathrm{~min}$. at $20^{\circ}$ (initial temperature) led to varying losses 


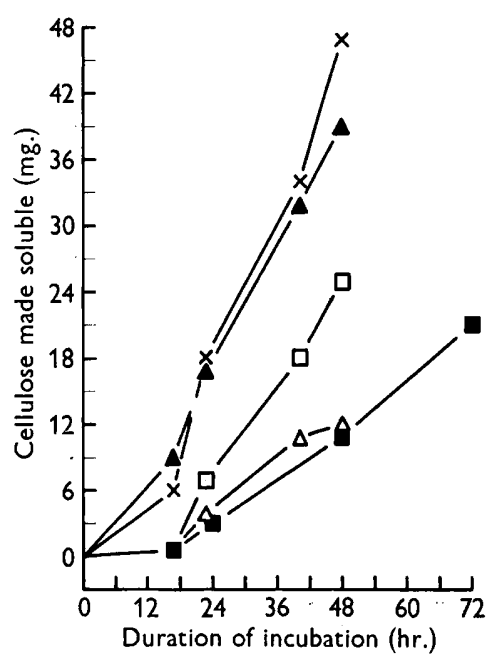

Fig. 1

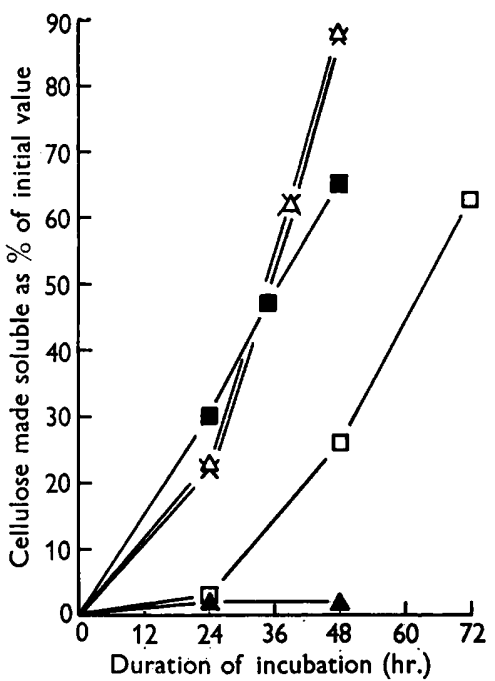

Fig. 2

Fig. 1. The effect of cellulose concentration on cellulolysis by rumen liquor. Cellulose powder (Whatman), initial weights $14 \mathrm{mg} . \triangle, 31 \mathrm{mg} . \square, 54 \mathrm{mg} . \Delta, 71 \mathrm{mg} . \times$. Native cotton fibres, initial weight $30 \mathrm{mg}$. a. $1 \mathrm{ml}$. rumen liquor. Total volume to $8 \mathrm{ml}$. with bicarbonate salts buffer, $\mathrm{pH} 6 \cdot 8$.

Fig. 2. The effect of total assay volume and of shaking on cellulolysis by rumen liquor. Total volume of $4 \mathrm{ml} . \square$, of $8 \mathrm{ml}$. $\Delta$, of $12 \mathrm{ml}$. $\times$. Effect of shaking in a total volume of $4 \mathrm{ml}$. $4 \mathrm{ml}$. shaken throughout $\Delta, 4 \mathrm{ml}$. shaken for first $24 \mathrm{hr}$. only $\square$. Rumen liquor, $1 \mathrm{ml}$. Initial cellulose powder (Whatman), $50 \mathrm{mg}$.

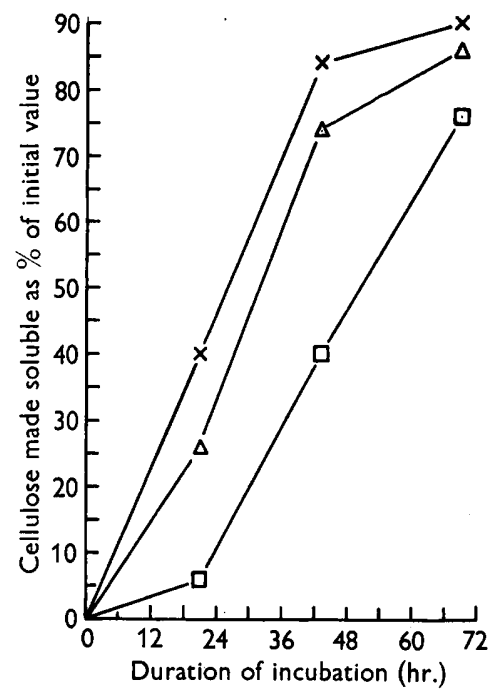

Fig. 3. The effect of rumen liquor concentration on cellulolysis. Rumen liquor, $0 \cdot 4 \mathrm{ml} . \square$, $0.8 \mathrm{ml}$., $\triangle, 2.0 \mathrm{ml}$., $\times$; initial cellulose powder (Whatman) $50 \mathrm{mg}$.; total volume $8 \mathrm{ml}$., bicarbonate-salts buffer, pH $6 \cdot 8$. 
Table 1. Effect of composition of the bicarbonate salts medium on cellulolysis by rumen liquor and by rumen liquor concentrates

Standard cellulose assay unless stated otherwise.

Conditions with rumen liquor

Cellulose made soluble in $40 \mathrm{hr}$. as \% of initial

1. Control, in bicarbonate $+\mathrm{CO}_{2}$ buffer (pH 6.8) with $\mathrm{KCl}, \mathrm{CaCl}_{2}$, $\mathrm{KH}_{2} \mathrm{PO}_{4}, \mathrm{MgSO}_{4},\left(\mathrm{NH}_{4}\right)_{2} \mathrm{HPO}_{4}$

2. As (1) but not $\mathbf{K C l}$.

3. As (1) but $\mathrm{KCl}$ at $25 \times$ concentration

4. As (1) but no $\left(\mathrm{NH}_{4}\right)_{2} \mathrm{HPO}_{4}$

5. As (1) but no $\mathrm{MgSO}_{4}$

6. As (1) but containing only bicarbonate, $\mathrm{MgSO}_{4}$ and $\left(\mathrm{NH}_{4}\right)_{2} \mathrm{HPO}_{4}$

7. As (6) but containing only bicarbonate and $\mathrm{MgSO}_{4}$ (no $\left(\mathrm{NH}_{4}\right)_{2} \mathrm{HPO}_{4}$ )

8. As (6) but containing only bicarbonate and $\left(\mathrm{NH}_{4}\right)_{2} \mathrm{HPO}_{4}$ (no $\mathrm{MgSO}_{4}$ )

9. As (6) but containing $\mathrm{MgSO}_{4}$ at $0.2 \times$ concentration

10. As (6) but containing $\mathrm{MgSO}_{4}$ at $5 \times$ concentration

11. As (6) but containing $\mathrm{MgSO}_{4}$ at $25 \times$ concentration

12. As (1) but containing $\mathrm{CaCl}_{2}$ at $30 \times$ concentration

13. As (1) but containing no $\mathrm{CaCl}_{8}$

14. As (1) but containing no $\mathrm{KH}_{2} \mathrm{PO}_{4}$

15. As (1) but containing $0.013 \mathrm{M}$-acetic acid (final concentration) pH 6.8

16. As (1) but no bicarbonate and no $\left(\mathrm{NH}_{4}\right)_{2} \mathrm{HPO}_{4}\left(\mathrm{NH}_{4} \mathrm{Cl}\right.$ replaces $\left(\mathrm{NH}_{4}\right)_{2} \mathrm{HPO}_{4} ; \mathrm{KH}_{2} \mathrm{PO}_{4}+\mathrm{NaOH}+\mathrm{N}_{2}(\mathrm{pH} \mathrm{6.8)}$ replaces bicarbonate- $\mathrm{CO}_{2}(\mathrm{pH} 6.8)$ )

17. As (16) but containing also bicarbonate $+\mathrm{CO}_{2}$ at same concentration as (1) i.e. total $\mathrm{PO}_{4}$ concentration now as in (16) i.e.; $11 \times$ control (1)

18. As (1) but containing $0.03 \% \mathrm{Na}_{2} \mathrm{~S}$ (final)

Conditions with concentrates (R.P.)

1. Control, in bicarbonate $+\mathrm{CO}_{2}$ buffer $\mathrm{pH} 6.8$ with $\mathrm{KCl}, \mathrm{CaCl}_{2}$, $\mathrm{KH}_{2} \mathrm{PO}_{4}, \mathrm{MgSO}_{4}$ and $\left(\mathrm{NH}_{4}\right)_{2} \mathrm{HPO}_{4}$

2. As (1) but in addition $0.03 \% \mathrm{Na}_{2} \mathrm{~S}$ (final)

3. As (1) but in addition $0.05 \mathrm{M}-\mathrm{K}_{3} \mathrm{Fe}(\mathrm{CN})_{6}$ (final)

4. As (1) but in addition $0 \cdot 13 \%$ gelatin (final)

5. As (1) but in addition $0 \cdot 25 \mathrm{M}$-sucrose (final) and $0.02 \mathrm{M}-\mathrm{NaCl}$ (final)

6. As (1) but in addition $0.02 \mathrm{M}-\mathrm{NaCl}$ (final)

7. As (1) but in addition $0 \cdot 1 \mathrm{M}-\mathrm{NaCl}$ (final)

8. As (1) but at $\mathrm{pH} 6 \cdot 6$

9. As (1) but at pH $6 \cdot 6$ and in addition, rumen liquor supernatant fluid (R.L.S.)

10. As (1) but at pH 5.9
66

52

18

20

60

16

13

36

48

46

0

60

60

69

o

56

66

88

86

1

88

40

88

46

86

86

o

in activity. Thus, after centrifugation, the precipitated micro-organisms and the supernatant fluid of rumen liquor were: (1) remixed in the same vessel, or (2) the supernatant fluid was rejected and replaced by the standard bicarbonate + salts buffer ( $\mathrm{pH} \mathrm{6 \cdot 8)}$. The two suspensions were immediately assayed on cellulose powder (Whatman); the first treatment produced $66 \%$ hydrolysis of the cellulose and the second gave only $25 \%$ hydrolysis. A control which had remained untreated at $20^{\circ}$ for 30 min. gave $87 \%$ hydrolysis of cellulose powder 
(Whatman), whilst the clear supernatant fluid which had been removed had no action on the cellulose. When centrifugation was done at $0^{\circ}$ and in presence of sodium sulphide $(0.03 \%)$ as in the standard procedure for making the deposit of rumen organisms (see Methods) followed by treatment (2) above, the suspension effected $54 \%$ hydrolysis of cellulose.

An alternative procedure for fractionation and concentration involved the use of a glass tube $3.0 \mathrm{~cm}$. diameter $\times 150 \mathrm{~cm}$. which was completely filled with rumen liquor ( $\mathrm{pH} \mathrm{6.7)}$ and closed. The liquor was then allowed to settle for $25 \mathrm{hr}$. at $1^{\circ}$, during which time three layers were produced. They were carefully separated by pipette and analysed for cellulolytic activity by the standard procedure. A control was subjected to the same treatment, but remixed without separation of phases and then assayed on cellulose powder (Whatman). No loss of cellulolytic activity resulted. The three layers which were separated provided the following data: (1) an upper layer with low activity and large volume (19\% of total cellulolytic activity of the control); (2) second layer of high activity and small volume (15\% of cellulolytic activity of control); (3) a precipitate of high activity and small volume (9\% of cellulolytic activity of control). Thus the total recovery of cellulolytic activity from the three fractions amounted only to $43 \%$ of that of the original unfractionated rumen liquor and no single fraction offered any source of a concentrated form of enzyme. The losses were not due to removal of soluble essential factors from the precipitated micro-organisms as was shown by addition of the supernatant fluid (R.L.S.) to these deposited organisms, when no improvement followed.

Various antiseptics were added to the standard assay mixture containing rumen liquor. It was found that $\mathrm{NaF}$ (final concentration $0.02 \mathrm{M}$ ) acted immediately, whether added at $0 \mathrm{hr}$. or after $24 \mathrm{hr}$. fermentation of the rumen liquor + cellulose mixture. When added at the beginning of fermentation, cellulolysis in $48 \mathrm{hr}$. was decreased from $50 \%$ (control in absence of $\mathrm{NaF}$ ) to $2 \%$ of the initial cellulose powder (Whatman). When $\mathrm{NaF}$ was added after $24 \mathrm{hr}$. of fermentation, the amount of cellulose powder hydrolysed $(48 \mathrm{hr}$.) amounted to only $10 \%$ as compared with the control values of $7 \%$ at $24 \mathrm{hr}$. and of $50 \%$ at $48 \mathrm{hr}$. Thus, in the hydrolysis of the cellulose powder by rumen liquor $+\mathrm{NaF}$, no more than $2 \%$ or $3 \%$ of the available cellulose was solubilized in $48 \mathrm{hr}$. or $24 \mathrm{hr}$., respectively. It appears that the principal enzymic action in presence of $\mathrm{NaF}$ is on associated polysaccharide material rather than on true cellulose. Similar experiments were carried out using thymol at a concentration sufficient to saturate the medium in the standard assay in presence of rumen liquor. The incubation was prolonged to $\mathbf{7 2} \mathrm{hr}$. to obtain a greater possible hydrolysis. In absence of thymol $84 \%$ of the cellulose powder (Whatman) disappeared, whereas thymol produced complete loss of the cellulolytic activity of rumen liquor. Under identical conditions toluene $(12 \%, v / v)$ permitted only $4 \%$ hydrolysis of cellulose powder. Hence, all these inhibitors produced almost total loss of true cellulolytic power. 


\section{Role of protozoa in cellulolysis by rumen liquor}

In view of the alleged role of protozoa in cellulose metabolism by rumen liquor a detailed examination was made to determine their possible importance. In collaboration with Drs A. E. Oxford and M. Eadie (for oligotrichs) and Dr G. Thomas (for holotrichs) of this Institute, representative organisms of the holotrich and oligotrich population normally frequenting the rumen were examined for their cellulolytic activity.

The holotrich protozoa were isolated by the method of Masson \& Oxford (1951) and of Oxford (1951). The concentrated protozoa were then washed several times, by decantation, with the acetate buffer of Sugden (1953). Subsequent disintegration of the organisms by freezing and thawing followed by centrifugation and filtration through a bacteriological glass filter provided a pale yellow extract of $\mathrm{pH}$ value $6 \cdot \mathbf{0}$. This extract, however, exhibited no significant cellulolytic action on cellulose powder nor on hydrocellulose (from $11 \mathrm{~N}-\mathrm{HCl}$ ). The absence of cellulase activity from rumen holotrichs is not altogether unexpected, for such organisms are more adapted to the metabolism of starch and soluble carbohydrates. On the other hand, oligotrichs are believed to be concerned with the digestion or ingestion of cellulose.

In order to avoid the difficulties encountered in separating the holotrichs from the oligotrichs of rumen liquor, advantage was taken of the relative paucity of holotrichs in a particular animal (Sheep no. 91). Oligotrichs were isolated by the procedure of Sugden (1953) and washed repeatedly with acetate + sulphide buffer ( $\mathrm{pH} 6 \cdot 8$ ), until a 60 -fold concentration of the original rumen liquor organisms was achieved. The protozoal fraction was then assayed for cellulolytic activity on cellulose powder in: (1) the above acetate + sulphide buffer as normally employed for oligotrich metabolism; (2) the $\mathrm{NaHCO}_{3}+$ sulphide buffer which, as previously shown, is well suited for cellulolysis by rumen liquor bacteria in the standard 'cellulase' assay. No extraneous source of $\mathrm{N}$ was supplied (e.g. R.L.S.). After incubation for 5 days at $37^{\circ}, 10 \%$ of the cellulose powder (Whatman) was solubilized in the acetate medium, as compared with $86 \%$ in the $\mathrm{NaHCO}_{3}$ medium.

More oligotrich protozoal suspensions were now prepared in a similar manner, but from the rumen liquor of a different sheep (no. 44) which contained a normal mixed fauna of oligotrich and holotrich protozoa. The 14-fold concentrate (15 mg. dry wt./ml. suspension) so obtained was then examined for cellulolytic action on cellulose powder (Whatman), but with the addition of rumen liquor supernatant fluid (which itself is inactive on this cellulose powder) in both the acetate + sulphide and $\mathrm{NaHCO}_{3}+$ sulphide buffers. The unconcentrated rumen liquor of sheep no. 44 was also examined for cellulolytic activity in $\mathrm{NaHCO}_{3}+$ sulphide medium. Table 2 summarizes the results.

The $\mathrm{pH}$ value of the bicarbonate + sulphide cultures rose to a higher value than normally found in the standard rumen liquor assay. This effect probably resulted from the extended time of the fermentation ( 5 days). The protozoa survived in acetate buffer during the whole of the fermentation period, whereas in the bicarbonate medium they rarely lived more than 1 or 2 days. 
A turbidity developed in the acetate and bicarbonate tubes during the fermentation and microscopic examination confirmed its bacterial nature. The bacterial flora presumably account for the almost total utilization $(83 \%)$ of cellulose in bicarbonate medium in contrast to the acetate medium, where, although active oligotrich protozoa were present, cellulolysis amounted only to $36 \%$. Hence, despite extensive washing and concentration procedures on the protozoa, with simultaneous dilution and rejection of bacteria, it would appear that sufficient bacteria survived, possibly engulfed by protozoa, to effect marked cellulolysis in bicarbonate, even after death of the oligotrichs.

\section{Table 2. Cellulolysis by washed suspensions of protozoa and by rumen liquor in acetate and in bicarbonate media}

Conditions: standard cellulase assay, but in bicarbonate + sulphide $(0 \cdot 02 \%, w / v)$ or in acetate + sulphide $(0.02 \%)$ buffer (Sugden, 1953) with addition of rumen liquor supernatant fluid (R.L.S.) where indicated. Activity of protozoa refers to the presence of living (motile) organisms $(+)$ or dead $(-)$ on microscopic examination. 14-fold concentrate of protozoa used. Rumen liquor (R.L.), $1 \mathrm{ml}$. neat, added. Cellulose utilization given at 5 th day of incubation. R.L.S. obtained from supernatant of R.L. after centrifugation $20,000 \mathrm{~g}$, $1^{\circ}, 30 \mathrm{~min}$.

\begin{tabular}{|c|c|c|c|c|c|c|c|c|}
\hline \multirow[b]{2}{*}{ Organisms } & \multirow[b]{2}{*}{ Medium } & \multirow[b]{2}{*}{ Additions } & \multicolumn{2}{|c|}{$\mathrm{pH}$ value } & \multicolumn{3}{|c|}{$\begin{array}{c}\text { Activity of } \\
\text { protozoa after } \\
\text { (days) }\end{array}$} & \multirow{2}{*}{$\begin{array}{c}\text { Cellulose } \\
\text { used as } \\
\% \text { of } \\
\text { available }\end{array}$} \\
\hline & & & Initial & (5 days) & 1 & 4 & 5 & \\
\hline Protozoa & Acetate $+\mathrm{Na}_{2} \mathrm{~S}$ & R.L.S. & $6 \cdot 7$ & $7 \cdot 1$ & + & + & + & 36 \\
\hline Protozoa & $\mathrm{NaHCO}_{3}+\mathrm{Na}_{2} \mathrm{~S}$ & R.L.S. & $7 \cdot 1$ & $8 \cdot 5$ & + & - & - & 83 \\
\hline R.L. & $\mathrm{NaHCO}_{3}+\mathrm{Na}_{2} \mathrm{~S}$ & None & $7 \cdot 0$ & $8 \cdot 3$ & . & . & . & 80 \\
\hline
\end{tabular}

The role of rumen liquor supernatant fluid in increasing the cellulolysis in acetate buffer threefold (10\% in sheep 91 to $36 \%$ in sheep 44 ) appears difficult to define clearly, for at least two reasons. First, the rumen liquor fluid has no action on the breakdown of cellulose by rumen bacteria in bicarbonate buffer, as already shown above. Secondly, the rumen liquor fluid has no beneficial action in prolonging life of oligotrich protozoa (Sugden, 1953). However, it is not unlikely that rumen liquor fluid may stimulate the development in acetate buffer of those bacteria, ingested by or otherwise closely associated with protozoa, which are capable of attacking cellulose.

In order to determine whether cellulolysis by protozoal preparations was in fact due to bacterial contaminants, subsequent experiments were undertaken under aseptic conditions. Protozoal fractions were obtained as in previous experiments, but from a mixture of equal volumes of rumen liquor of sheep no. 44 (mixed protozoa) and of sheep no. 91 (almost holotrich-free). The 30-fold concentrate was then allowed to metabolize cellulose powder (Whatman) in presence of rumen liquor fluid in acetate + sulphide or bicarbonate + sulphide media, under sterile conditions (Table 3A). After 3 days of fermentation the protozoa appeared far more active in the acetate-containing medium, whereas the bicarbonate-containing medium contained many dead or sluggish ciliates. Examination of cultures from the acetate- and from the 
bicarbonate-media indicated the presence of Gram-negative cocci as the main bacterial flora.

Table 3. Cellulolysis by washed suspensions of protozoa in acetate and in bicarbonate media

Conditions: as in Table 2. C.P.W.= cellulose powder, Whatman; H.C.H.=hydrocellulose, from $\mathrm{HCl}$ treatment; Cellulose utilization given at 3rd day of incubation. Protozoa from 30-fold concentrate of R.L. Experiments A under sterile conditions.

\begin{tabular}{|c|c|c|c|c|c|c|c|c|}
\hline \multirow[b]{2}{*}{ Medium } & \multirow[b]{2}{*}{ Substrate } & \multirow[b]{2}{*}{ Additions } & \multicolumn{2}{|c|}{$\mathrm{pH}$ value } & \multicolumn{3}{|c|}{$\begin{array}{l}\text { Activity of } \\
\text { protozoa after } \\
\text { (days) }\end{array}$} & \multirow{2}{*}{$\begin{array}{c}\text { Cellulose } \\
\text { used as } \\
\% \text { of } \\
\text { available }\end{array}$} \\
\hline & & & Initial & (3days) & 1 & 2 & 3 & \\
\hline $\begin{array}{l}\text { A. Acetate }+\mathrm{Na}_{2} \mathrm{~S} \\
\mathrm{NaHCO}_{3}+\mathrm{Na}_{2} \mathrm{~S}\end{array}$ & $\begin{array}{l}\text { C.P.W. } \\
\text { C.P.W. }\end{array}$ & $\begin{array}{l}\text { R.L.S. } \\
\text { R.L.S. }\end{array}$ & $\begin{array}{l}6 \cdot 7 \\
7 \cdot 0\end{array}$ & $\begin{array}{l}7 \cdot 3 \\
7 \cdot 6\end{array}$ & $\begin{array}{l}+ \\
+\end{array}$ & $\begin{array}{l}+ \\
+\end{array}$ & $\begin{array}{l}+ \\
+\end{array}$ & $\begin{array}{r}7 \\
42\end{array}$ \\
\hline 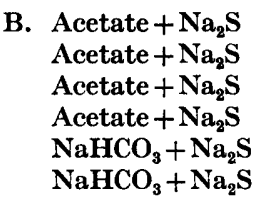 & $\begin{array}{l}\text { C.P.W. } \\
\text { H.C.H. } \\
\text { C.P.W. } \\
\text { H.C.H. } \\
\text { C.P.W. } \\
\text { H.C.H. }\end{array}$ & $\begin{array}{l}\text { None } \\
\text { None } \\
\text { R.L.S. } \\
\text { R.L.S. } \\
\text { R.L.S. } \\
\text { R.L.S. }\end{array}$ & $\begin{array}{l}. \\
. \\
. \\
.\end{array}$ & $\begin{array}{r}\dot{.} \\
\dot{.} \\
\dot{.}\end{array}$ & $\begin{array}{r}\cdot \\
\dot{.} \\
\dot{.} \\
\dot{.}\end{array}$ & $\dot{.}$. & $\begin{array}{l}\dot{5} \\
\dot{5} \\
\dot{5}\end{array}$ & $\begin{array}{r}0 \\
0 \\
23 \\
0 \\
81 \\
77\end{array}$ \\
\hline
\end{tabular}

Other workers (see 'Methods and substrates') have used a hydrocellulose (from $\mathbf{H C l}$ ) in studies of protozoal cellulolysis. In order to see whether such a substrate was more susceptible to hydrolysis than was cellulose powder (Whatman) we examined the action of our protozoal preparations on a similar hydrocellulose. Protozoa were concentrated (30-fold) from mixed rumen liquors of sheep nos. 91 and 44 and allowed to metabolize cellulose powder (Whatman) or the hydrocellulose, in presence or absence of rumen liquor fluid (Table $3 \mathrm{~B}$ ). The protozoa were alive for at least $24 \mathrm{hr}$. after inoculation and all living organisms of Metadinium medium examined as well as some of the dead specimens contained ingested particles of cellulose. As found previously rumen liquor fluid assists the organisms (bacteria and/or protozoa) to hydrolyse cellulose in the acetate medium. Cellulolysis in the bicarbonate medium (therefore principally bacterial in nature) proved to be far more effective.

\section{DISCUSSION}

In work involving cellulolytic enzymes, either from the rumen or from alternative sources, it is important to emphasize that results are determined not only by the substrate, but also by the method of analysis. Different forms of cellulose, from native cotton fibres through the degraded states of hydrocellulose, precipitated cellulose and cellodextrins to the cellulose derivative carboxymethylcellulose, contain chains of similar chemical structure, but of very different lengths. Furthermore, carboxymethylcellulose is not even a true chemical cellulose, but rather a soluble cellulose derivative. The action of pure isolates of rumen organisms, or of mixed rumen micro-organisms, on any one form of 'cellulose' is no proof that other substrates are likewise susceptible. However, as we have shown, mixed rumen liquor micro-organisms produce 
almost complete solubilization of all forms of cellulose, from the simplest types up to the highly complex cotton fibres. These results were achieved by determination of the residual cellulose after treatment with micro-organisms and thus avoided the errors inherent in determinations of reducing sugars (see below).

The earlier difficulties connected with the gravimetric estimation of cellulose, namely the presence of filter-impeding bacterial products, appear to have been overcome by our technique, which employed selected solvents. The latter, even when used in amounts up to 5 times the volumes quoted in the standard technique are not detrimental. The washing process is so effective that the apparent endogenous cellulose of rumen liquor is negligible or in the case of concentrated preparations of the organisms from the liquor does not exceed $4 \%$ of the cellulose used in the standard assay. We have also used the method in the determination of cellulolysis by pure strains of micro-organisms, e.g. Sporocytophaga myxococcoides (QM B 482) and Cellvibrio vulgaris (QM B 4) and Myrothecium verrucaria (I.M.I. 45541), with equally satisfactory results.

On the other hand, determination of cellulolysis by sugar formation from insoluble cellulose preparations makes no allowance for associated glucosans or xylans of relatively low molecular weight which may be solubilized under the assay conditions. In presence of enzyme(s) not necessarily 'cellulolytic', such non-cellulosic non-reducing fractions may well be hydrolysed to sugars. This effect assumes major importance when the observed cellulolysis never exceeds more than a fraction of the available cellulose. This appears to be the case in the work of Meites, Burrell \& Sutton (1951), of Kitts \& Underkofler (1954) and of Hungate (1942, 1943, 1950 b). Meites et al. (1951), with ground filter-paper and rumen micro-organisms in presence of toluene, obtained in $120 \mathrm{hr} .4 \%$ of hydrolysis as measured by sugar production. Kitts \& Underkofler (1954) found that mixed rumen micro-organisms attacked soluble carboxymethylcellulose much more effectively than they did filter-paper or Alphacel (a cellulose powder). Thus, in presence of thymol, $\mathrm{NaF}$ or toluene rumen micro-organisms achieved, as determined by sugar analyses, approximately $60 \%$ hydrolysis of susceptible links in carboxymethylcellulose and $14 \%$ hydrolysis of ground filter-paper (calculations by present author) in $48 \mathrm{hr}$. Hungate (1942) obtained qualitative evidence (Benedict test and glucosazone formation) of the action of a protozoal extract on hydrocellulose in presence of toluene.

The small degree of hydrolysis of insoluble cellulose powders by rumen micro-organisms in presence of antiseptics thus found by the above workers (by estimating reducing sugars) and also by ourselves ( $4 \%$ cellulolysis) represents, as we have shown, only a small fraction of their true (up to $84 \%$ ) cellulolytic capacity. Such low rates of cellulose hydrolysis may well represent enzymic breakdown of non-reducing fractions (xylans, glucosans) associated with relatively undegraded cellulose. Support for this proposal is seen in the chromatographic identification of xylose from an Alphacel + rumen microorganism incubation (Kitts \& Underkofler, 1954). Further evidence is given by the work of Huffman, Rabers, Spriesterbach \& Smith (1955) who isolated 
short-chain polysaccharides from filter-paper, wood cellulose and cotton linters by aqueous extraction.

The protozoal extract of Hungate described above may also have acted on a minor constituent of the cellulose or alternatively the activity of the extract might have been bacterial in origin. We have shown that, despite extensive washing of protozoa, sufficient bacteria to produce marked cellulolysis may remain. This might involve the cellulose seen to be ingested in both living and dead oligotrich protozoa and perhaps true 'cellulase', secreted by ingested bacteria, is more stable within the protozoa than in the medium. The slight degree of hydrolysis of cellulose obtained in the work cited was presumably effected by an enzyme different from that which hydrolyses true cellulose (cf. Reese, Siu \& Levinson, 1950). The former enzyme system, in rumen micro-organisms, appears to be relatively stable to agitation (cf. Meites $e t$ al. 1951) and to antiseptics. However, the true cellulolytic activity of rumen micro-organisms is, as we have shown, extremely sensitive to a variety of conditions, including agitation, antiseptics and all attempts at concentration. From the present results on cellulolysis it seems evident that hydrolysis is much greater in a bicarbonate medium (conducive to bacterial growth) than in acetate buffer (as used for protozoal cultivation). Whether or not the protozoa survived in either medium appears unimportant for cellulolysis provided the associated bacteria flourish. This suggests that rumen protozoa owe much, if not all, of their cellulolytic activity to the presence of their associated bacterial commensals.

The author wishes to express his sincere thanks to Dr G. A. Levvy for his interest and encouragement, to Dr J. Conchie for the extract of Patella vulgata, to Mr J. Munro for valuable technical assistance, and to Dr H. S. Levinson for the strains of Sporocytophaga and of Cellvibrio.

\section{REFERENCES}

Aitken, R. A., Eddy, B. P., Ingram, M. \& Weurman, C. (1956). The action of culture filtrates of thef ungus Myrothecium verrucaria on $\beta$-glucosans. Biochem.J. 64,63 .

Basu, S. N. \& PaL, P. N. (1956). Unfavourable effect of shaking on fungal cellulases. Nature, Lond. 178, 312.

Bryant, M. P. \& Burkey, L. A. (1953). Cultural methods and some characteristics of some of the more numerous groups of bacteria in the bovine rumen. J. Dairy Sci. 36, 205.

ELSDEN, S. R. (1945). The fermentation of carbohydrates in the rumen of the sheep. J. exp. Biol. 22, 51.

Higa, H. H., O'Neill, R. D. \& Jennison, M. W. (1956). Partial purification of cellulase from a wood rotting Basidiomycete. J. Bact. 71, 382.

Huffman, G. W., Rabers, P. A., Spriesterbach, D. R. \& Smith, F. (1955). Nature of a hemicellulose extracted from cellulose with water. Nature, Lond. 175, 990.

Hungate, R. E. (1942), The culture of Eudiplodinium neglectum, with experiments on the digestion of cellulose. Biol. Bull., Woods Hole, 83, 303.

Hungate, R. E. (1943). Further experiments on cellulose digestion by protozoa in the rumen of cattle. Biol. Bull., Woods Hole, 84, 157.

Hungate, R. E. (1950a). The anaerobic mesophilic cellulolytic bacteria. Bact. Rev. 14, 1 . 
Hungate, R. E. (1950b). Mutualisms in protozoa. Annu. Rev. Microbiol. 4, 53.

Jermyn, M. A. (1952). Fungal cellulases. 1. General properties of unpurified enzyme preparations from Aspergillus oryzae. Aust. J. sci. Res. B, 5, 409.

KitTs, W. D. \& Underkofler, L. A. (1954). Digestion by rumen micro-organisms. Hydrolytic products of cellulose and the cellulolytic enzymes. J. Agric. Food Chem. 2, 639.

Masson, F. M. \& OxFond, A. E. (1951). The action of the ciliates of the sheep's rumen upon various water soluble carbohydrates, including polysaccharides. J. gen. Microbiol. 5, 664.

Meites, S., Burrell, R. C. \& Sutton, T. S. (1951). Factors influencing the in vitro digestion of cellulose by rumen liquor in presence of an antiseptic. J. Anim. Sci. $10,203$.

Nishizawa, K. \& Kobayashi, T. (1953). Cellulose splitting enzymes. 11. Mode of actir $n$ of Irpex cellulase on its substrates. J. Agric. chem. Soc. Japan. 27, 239.

OxFord, A. E. (1951). The conversion of certain soluble sugars to a glucosan by holotrich ciliates in the rumen of sheep. J. gen. Microbiol. 5, 83.

Phillipson, A. T. (1953). Digestion of cellulose by the ruminant. In Biological Transformations of Starch and Cellulose. Symp. biochem. Soc. 11, 63.

Phillipson, A. T. \& Cuthbertson, D. P. (1956). Modern concepts of rumen digestion and metabolism. 7th Int. Congr. Anim. Husb., Madrid, Subject 6, p. 1.

REESE, E. T., SiU, R. G. H. \& Levinson, H. S. (1950). The biological degradation of soluble cellulose derivatives and its relationship to the mechanism of cellulose hydrolysis. J. Bact. 59, 485 .

Sijpesteisn, A. K. (1951). On Ruminococcus flavefaciens, a cellulose decomposing bacteria from the rumen of sheep and cattle. J. gen. Microbiol. 5, 869 .

Siv, R. G. H. (1951). Microbial Decomposition of Cellulose. New York: Reinhold Publ. Corporation.

Sugden, B. (1953). The cultivation and metabolism of oligotrich protozoa from the sheep's rumen. J. gen. Microbiol. 9, 44.

Thomas, R. (1956). Fungal cellulases. VII. Stachybotrys atra: production and properties of the cellulolytic enzyme. Aust. J. biol. Sci. 9, 159.

WALSETH, C. S. (1952). Occurrence of cellulases in enzyme preparations from microorganisms. Tech. Pap., Pulp. Pap. Ind. N.Y. 35, 228.

Whitaker, D. R. (1953). Purification of Myothecium verrucaria cellulase. Arch. Biochem. Biophys. 43, 253.

(Received 20 February 1957) 